\title{
REASONS AS TO WHY CONSUMER PREFERS ONE BRAND OVER ANOTHER: A STUDY OF PACKAGED MILK IN HYDERABAD USING BLIND TESTS
}

\author{
Khizer Hayat Khuhawar \\ Shaheed Zulfikar Ali Bhutto Institute of Science and Technology \\ (SZABIST) \\ Muhammad Ali Memon \\ University of Sindh \\ Asadullah Shaikh \\ Ilma University \\ Hyder Ali Nizamani \\ University of Sindh \\ Majid Hussain Memon \\ Quaid-e-Awam university,awabshah
}

\begin{abstract}
Purpose:-This paper highlights the changing trends in the consumption patterns of consumers in Hyderabad with regard to packaged milk

Methodology:-The society here is getting educated, which paves way for the packaged milk firms to market the benefits of their product and warn their consumers of the harm of the loose milk.

Findings:-The paper concludes with the proportion of factors that influence people in Hyderabad about preferring a brand over another.

Practical Implications:-This research paper tends to inform the firms in the packaged milk industry about the increasing demand of their product and the ways they can cope up with the upcoming demand.
\end{abstract}

Keywords: Packaged Milk, Loose milk, Quality, Liquid Dairy Products (LDP)

Jel Classification: M31, M11, M10

*The material presented by the author does not necessarily portray the view point of the editors and the management of the Ilma University - Formerly IBT

1. khizer Hayat Khawar :

khizershayat@gmail.com

2. Muhammad Ali Memon: muhammad.ali@usindh.edu.pk

3. Asadullah Shaikh : asshaikh@nu.edu.sa

4. Hyder Ali Niz : shaikhasad@hotmail.com

5. Majid Hussain: Memonmajidhussain@quest.edu.pk

CILMA-JBS is published by the Ilma University - Formerly IBT Main Ibrahim Hydri Road, Korangi Creek, Karachi-75190, Pakistan. 


\section{INTRODUCTION}

In 1981 the packaged-milk was first acquainted in Pakistan, which was not embraced by people initially. This was because people were not aware of the Tetra Packaging and they were acquainted with the loose milk. The loose milk is quite hazardous to health because it is contaminated by water by the local distributors. But people until then, believed loose milk to be better. The packaged milk, then came up with the heavy advertising of the Tetra Packaging which conveyed the ways in which it is better than the loose milk. Now today the market is filled with the packaged milk products, out of which the major players are Nestle Milk Pak and Olper's Milk (which are the blind test sources in the study).

Consumer preference is not an easy thing to deal with; rather it requires careful actions by the companies to take the necessary steps by which consumers can prefer their brand and not the others. This research focuses as to why the consumers of Nestle and Olper's prefer the respective brands and what are the solid grounds on which they show patronage towards the brands. This is carried out using the blind test. The test used single blind product test which involves two parties, one is the administering party (which conducts the test) and the test subject (respondents). In single blind product test, it is only the administering party, who knows about the brand involved. The main factors under consideration are Price, Taste, Quality, Advertising, Packaging, Smell, Thickness, Color, Pack Design, and Brand Image.

On the chosen parameters, the study found that people preferred Olper's Milk than Milk Pak. This is because of the heavy advertising by the Olper's brand using family bonding as their basic theme. However, the quality of the milk was most preferred factor among all the other (Javaid, et al., 2009). This means when it comes to price versus quality, consumers are more inclined towards quality no matter how high the price is (Solomon, 2014). Since Pakistan is a developing country and the $6^{\text {th }}$ largest producer of milk in the world, the price of the milk can be borne by the users. Also milk is considered to be in the regular diet, thus the demand cannot diminish or even minimize in the country (FATIMA, WASIM, \& REHMAN, 2011).

The research paper is composed of 5 sections. Section 1 is introduction. Section 2 discusses the milk industry and the consumer preferences over the time. Section 3explains the 10 important factors of the study which influences heavily on changing the consumer's preferences. Section 4 gives the propositions for firms in milk industry to maintain and grow their current position. Finally, section 5 gives the conclusion.

\section{THE MILK INDUSTRY AND CONSUMER PREFERENCES OVER TIME}

Pakistan had a herd size of roughly 63 million animals which stood as the third largest in the world. Roughly 35 million Pakistani are earning their bread through business of dairy farming, extracting approximately $40 \%$ of their total income from livestock. The dairy animals raised by farmers use the milk for their homes and also sell a certain quantity that serves to be a part of their income. These animals in the Pakistani context are viewed as an important asset, which in case of financial downturns can help the owner to mitigate the risk. Pakistan due to poor economic fabric lacks the developed ways for storing and transporting 
milk. Currently more than $20 \%$ of milk production is lost due to poverty stricken economy. However being the $3^{\text {rd }}$ largest herd size of the world, Pakistan could have evolved the industry to a greater extent, but sadly it lacked governmental attention.

\subsection{Private Companies) Took the Charge of Storing and Transporting Milk Safely}

Out of $100 \%$ milk produced in Pakistan, merely 3\% is being processed. The remaining $97 \%$ of the milk is still untreated and sold by ordinary dairies in the country. This is because of the illiteracy of the people regarding the milk treatment procedures. The private owners of the milk business come into play then. They are highly trained and highly knowledgeable about the milk processing techniques. Thus they save almost $20 \%$ of the milk which is wasted due to lack of knowledge in transporting and storing milk. These private firms get the milk either from their own dairy settings or from local dairy farmers whom they trust. The competition among these firms is increasing the ways the milk is being processed and presented to the final consumer, which eventually increases the overall competition among private firms dealing in packaged milk.

\subsection{Consumer Preferences now and then}

The contemporary customer is well versed with the market trends and is well aware of which product suits him the best. Thanks to internet, customers now follow the word-ofmouth and reviews by other consumers about a product before actually purchasing a product. A survey which was conducted in 2005 resulted that only 3 to $4 \%$ of the total population prefers packaged milk whereas the rest of the populace still stick to the loose milk. However it is 2015 now, and after 10 years there has been an increased shift in milk preferences. Educated people have developed their tastes for milks, which is a welcoming factor for the new entrants.

Before the advent of the Tetra Pack, the consumers were inclined indefinitely with the loose milk. This was because many people earned their bread through dairy farming and in return their families showed the patronage for the milk and purchased from their families. The other reason was that there was no substitute for loose milk. People can either use loose milk directly or can breed a cow or buffalo and can directly milk from it.

However people today are well-aware that local dairies are contaminating the fresh milk with water which declines the quality of the milk. On the other side customers think that the packaged milk contains extraordinary preservatives which lead to zero effect on health even after consuming a so-called-packaged-milk.

\subsection{Growing Demand of Packaged Milk}

Pakistan is confronting an issue of increasing population day by day. Though this increasing population has some after effects on the economy, it has its more advantages in the form of giving birth to new consumer every day. The education pattern in Pakistan is increasing. The older generation, whether rich or poor, is directing their offspring to acquire education. Thus a more educated society is coming up. This educated society is very conscious about its health and hygiene. They are also well aware of the brands. Also the 
migration of people from rural to urban is giving a sharp increase to changing consumer preferences over branded products.

The increase in middle class population has led to an increase towards the packaged milk. In 2009, the LDP (liquid dairy products) was consumed by $19 \%$ per annum, which makes around 18.9 billion liters. According to this data, Pakistan stood as the $4^{\text {th }}$ largest country of LDP consumers in the world.

Not alone the urbanization or literacy rate in population is leading to an increase demand of packaged milk, but the economical price of the product being offered by the firms is also helping consumers to buy packaged milk rather than lose milk. An average family can easily buy a milk pack $(0.5 \mathrm{~L})$ only in $45 \mathrm{PKR}$ to make tea or to consume for health purpose. Similarly the products and competition like Olper's and Haleeb also come up with the same offering but with even more economical prices (Pakistan, 2010). In this way the competition is kept healthy and the consumer preferences keep changing on many factors, whether it be price, quality, quantity offered, advertising, brand personality, promotional offer, or celebrity endorsement (Khaqan, Siddiqui, \& Siddiqui, 2016).

\section{FACTORS OF CHANGING PREFERENCES IN PACKAGED MILK}

\subsubsection{Quality \& Price}

Quality is an integral element among the different factors of consumer preferences. Consumers primarily look for best quality either while buying any product or service. This notion has also been witnessed in this research article where consumers prefer quality comparatively more than other factors. Keeping the significance of quality, brands also focus more on quality and try to come up with such advertisements that provoke the high quality of their product and services.

This research too keeps the factor of price as one of the key factor, because in the case of packaged milk, it is being observed that consumers do not find much differences in the prices of different brands particularly Olpers and Milk Pak, hence they then make their decision on the basis of perceived quality along with other factors as well.

\subsubsection{Packaging \& Advertising}

As mentioned earlier that in the case of packaged milk, consumers do not find much price different therefore they have to consider other preferring factors that can motivate them to select and buy particular product. Among such factors, packaging then comes to play its role. Attractive packaging creates a good image and hence can help firms to position their product accordingly. Advertising is a key marketing concept that tries to elucidate the "behind the scene" process being done by firms. The aim is just to get closer to the consumers to ensure their satisfaction or to inform consumers of their upcoming changes in the products (Boyd, Westfall, \& Stasch, 1989).

\subsubsection{Taste \& Smell}

In the case of packaged milk, taste is an important element that differentiates one product with another. So companies have to keep focusing on taste. As per the finding of this research, it is clearly witnessed that different consumers perceive taste differently. Some of them prefer creamy factor, and some look for smoothness. 
Since the packaged milk has to go through different process of treatment, therefore the smell factor has particular position among the others factors of consumer preference. Perception varies from consumer to consumer. There are consumers who expect a natural smell, few of them prefer creamy smell and the variation goes on. But as per the finding of research article, smell is not the top factors in The Case Of Packaged Milk.

\subsubsection{Color \& Thickness}

Like smell, packaged milk has slightly different color in contrast with ordinary dairy milk. Color is a factor that has psychological influence. Different consumer prefer differently.

Smell, color and thickness, all these factors are the factors that differentiate packaged milk with ordinary dairy milk (Jawaid, Talpur, Nizamani, Memon, \& Khaskheli, 2015). As per the finding of this research article, it can be said that thickness plays an important role in the process of making decision. There are cases, when consumers prefer creamy factors and hence they look for feeling of thickness and those who look for natural feeling, have not preferred thickness that much

\subsubsection{Pack Design \& Brand Image}

Pack design is a product oriented concept as it is directly related to the product. It describes the appearance of the product and has an influence on consumers' mind. Therefore it is important for marketers to focus on this factor. Olpers in this case, takes lead.It can be said that all the above factors of consumer preferences are the basis of creating a desirable brand image. If firms are successful in getting over the above factors, resultantly then they can be successful in create a positive brand image. Moreover brand image is also associates with firms' CSR activities as well (Chaturvedi, 2011).

\subsection{Consumer Preferences in Hyderabad Level Of Satisfaction Towards Each Factors Of Brand Evaluation - Milk Pak}

Here it has been analyzed the factors for the brand evaluation. At first, different factors related the Milk Pak preferences are elaborated. It has been shown in the figures in percentage.

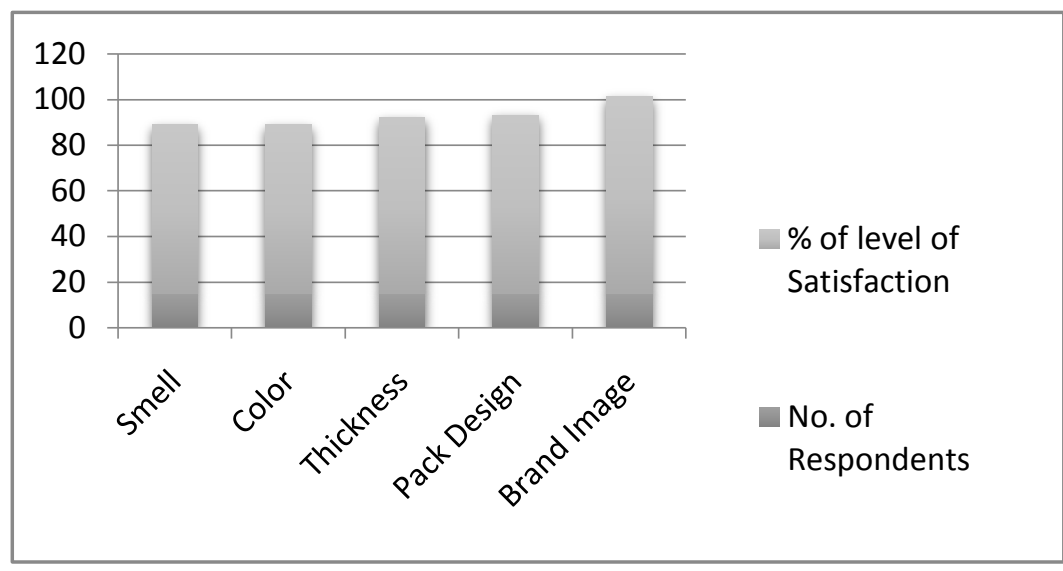

Figure.1 


\section{INFERENCES}

The diagram showing No. of respondents of Milk Pak, that is, 15 and their level of satisfaction towards each attribute. Smell and color with the lowest percentage (74) and Brand image with the highest $-86 \%$. Following are the calculations:

$>$ Total no. of Milk Pak respondents: 15

$>$ Grade Point: 10

$>$ Total: $15 \times 10=150$

$>$ Total grade points of each attribute given by total no. of Milk Pak respondents are calculated from questionnaire and is given below:

- Smell: 111 (sum of total grade points)

- Color: 111 (sum of total grade points)

- Thickness: 115 (sum of total grade points)

- Pack design: 117 (sum of total grade points)

- Brand Image: 129 (sum of total grade points)

Level of satisfaction is calculated as:

- Total No of Grade points of each factor / 150

\section{Level of satisfaction towards each Factor of Brand evaluation - Olper's}

Here it has been analyzed the factors for the brand evaluation. Now, it has been discussed about the attributes related the Olper's preference. It has been shown in the figures in percentage.

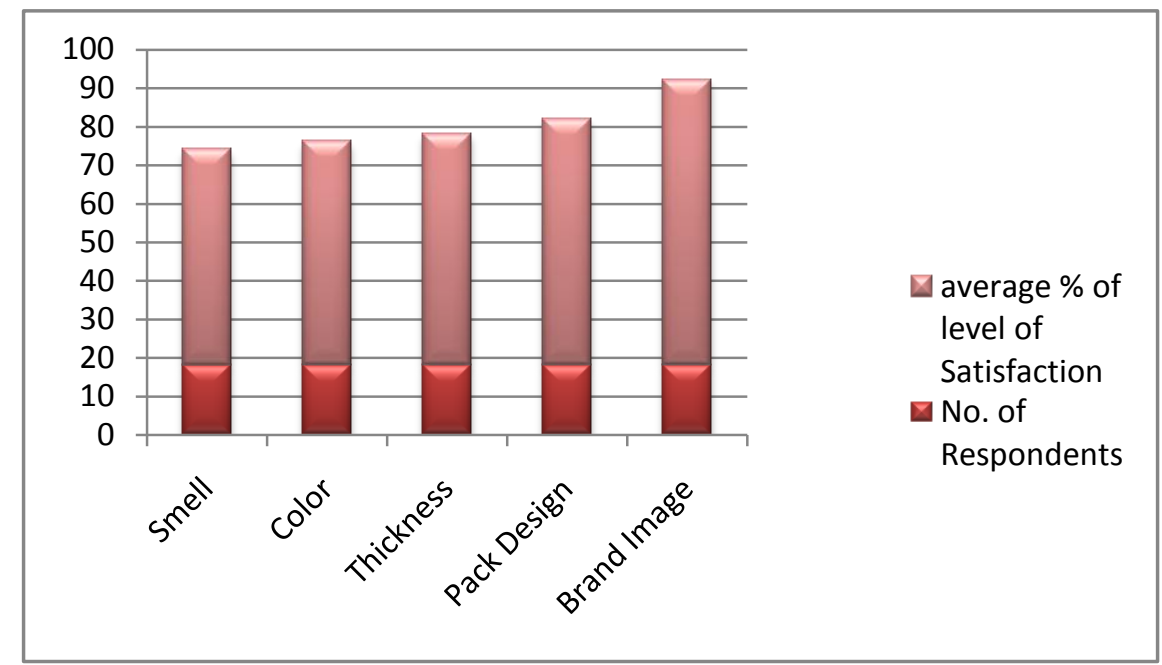

Figure. 2

\section{INFERENCE}

The diagram showing no. of respondents of Olper's that is, 18 and their level of satisfaction towards each attributes. Smell with the lowest percentage (56) and Brand image with the highest $-74 \%$. Following are the calculations:

$>$ Total no. of Olper's respondents: 18

$>$ Grade Point: 10

Total: $18 * 10=180$

$>$ Total grade points of each attribute given by total no. of Olper's respondents are calculated from questionnaire and is given below:
- Smell: 101 (sum of total grade points)
- Color: 104 (sum of total grade points)
○ Thickness: 108 (sum of total grade points) 
- Pack design: 115 (sum of total grade points)

- Brand Image: 133 (sum of total grade points)

Level of satisfaction is calculated as:

○ Total No of Grade points of each factor / 180

But the technical aspect of these figure is, if it is just compared, then these two figures that is, then it would say for example, Brand Image of Milk Pak won against Olper's, but this not the case, because, the no. of Olper's respondents is greater than Milk Pak. So if the no. of respondents of Olper's is equal to that of Milk Pak, than Olper's would win. Same is the case with each attribute.

According to this technical aspect, Olper's Brand Image has won against Milk Pak. But Olper's has lost in other attribute.

\section{Level of satisfaction towards each Factor of Brand evaluation - Milk Pak}

Here it has been analyzed about the factors for the brand evaluation. At first, report has explained the factors related the Milk Pak preference. It has been shown the figures in percentage.

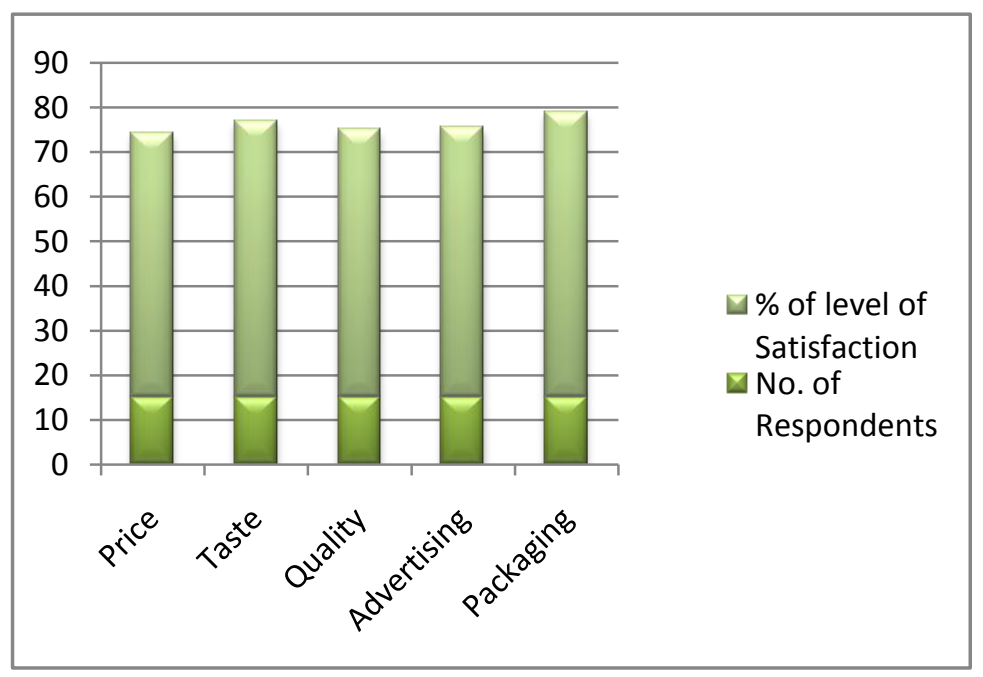

Figure .3

\section{INFERENCES}

The diagram is showing No. of respondents of Milk Pak, that is, 15 and their level of satisfaction towards each attributes. Smell and color with the lowest percentage (74) and Brand image with the highest $-86 \%$. Following are the calculations:

$>$ Total no. of Milk pak respondents: 15

$>$ Grade Point: 10

$>$ Total: $18 * 10=150$

$>$ Total grade points of each attribute given by total no. of Milk Pak respondents are calculated from questionnaire and is given below:

○ Price: 89 (sum of total grade points)

- Taste: 93 (sum of total grade points)

- Quality: 90 (sum of total grade points)

- Advertising: 91 (sum of total grade points)

- Packaging: 96 (sum of total grade points)

Level of satisfaction is calculated as:

○ Total No of Grade points of each factor /150 


\section{Level of satisfaction towards each Factor of Brand evaluation - Olper's}

Here it has been analyzed the factors for the brand evaluation. Now it has been discussed the factors related the Milk Pak preference. It has been shown the figures in percentage.

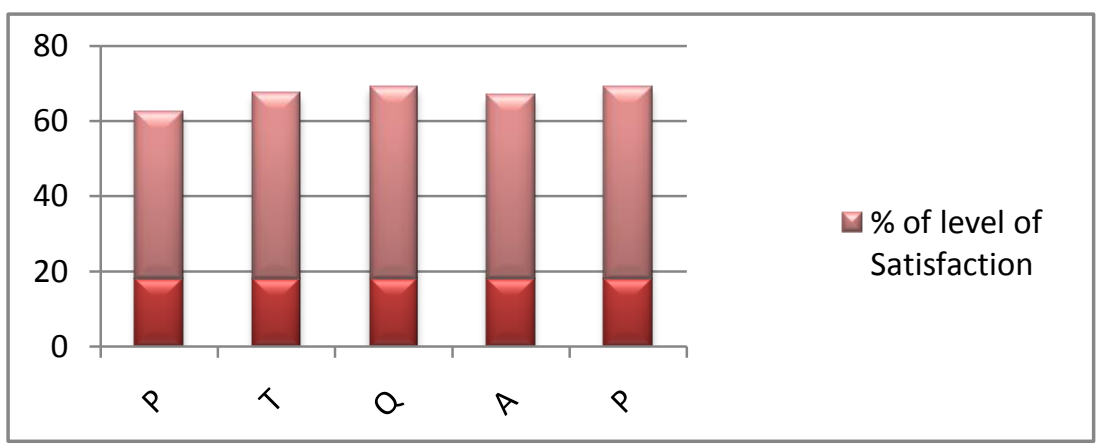

\section{INFERENCES}

Figure.4

The diagram showing No. of respondents of Olper's, that is, 15 and their level of satisfaction towards each attributes. Smell and color with the lowest percentage (74) and Brand image with the highest $-86 \%$. Following are the calculations:

$>$ Total no. of Milk Pak respondents: 18

Grade Point: 10

$>$ Total: $18 * 10=180$

$>$ Total grade points of each attribute given by total no. of Milk Pak respondents are calculated from questionnaire and is given below:

○ Price: 80 (sum of total grade points)

- Taste: 89 (sum of total grade points)

- Quality: 92 (sum of total grade points)

- Advertising: 88 (sum of total grade points)

- Packaging: 92 (sum of total grade points)

Level of satisfaction is calculated as:

- Total No of Grade points of each factor /180

\section{RECOMMENDATIONS}

According to the results of the survey it is clearly evident that consumers in Hyderabad prefer quality over all the other factors (Shaikh, et al., 2016). Since the consumers are becoming more educated every day, their preference for quality is increasing to a greater extent. So whether it's Milk Pak or Olper's, the firms must take care of the quality at most (Akhtar, 2015).

Since milk is an essential commodity in the diet of Pakistanis, same is the case in the Hyderabad. In this regard, taste plays a significant role. People prefer a thicker taste and less of smell. Therefore for the companies in packaged milk industry, it is highly recommended to develop a strong taste and strive to maintain that taste in order to remain preferred for longterm.

Advertising always hits the bulls-eye, only if it communicates the intended message to the consumers. Ads also play a great role in making a position in the customer's mind. Therefore 
while making ads, be careful and specific on what are you trying to communicate? Advertisements can make an enduring effect on the consumer perceptions and eventually their preferences. The next important thing to consider is the weight-age of the family decision over the purchase of the packaged milk. Mostly the females in the house are to decide for the purchase as they are the controllers of the kitchen. Olper's did extremely well in targeting the family decision factor by continuously exposing their target audience to ads that highlighted family values. Thus firms can use various family values to emphasize the consumption of milk.

Keeping in view the economic situation in Pakistan, the price of the packaged milk has to be kept nominal which can be afforded by every class in the society easily. With this factor, the packaging can be amalgamated, that is introduction of such a package that carries one glass of milk. In this way every customer can turn in to a consumer. Also the easy-to-use packaging of Milk Pak initially grabbed more consumers, so Olper's copied the same strategy and swept Milk Pak with a higher sales. Thus the packaging must be updated according to the needs of the consumers or it must be updated to be the need of the consumers.

\section{CONCLUSION}

This research paper tends to inform the firms in the packaged milk industry about the increasing demand of their product and the ways they can cope up with the upcoming demand. This article will serve the firms to update their activities within the context of the Hyderabad city.

\section{REFERENCES}

Akhtar, S. (2015). Food safety challenges - a Pakistan's perspective. Critical reviews in food science and nutrition, 55(2), 219-226.

Boyd, H. W., Westfall, R. L., \& Stasch, S. F. (1989). Marketing research: text and cases. McGraw-Hill/Irwin.

Chaturvedi, V. (2011). A Study on Factors Affecting Brand Preference Dimensions With Reference To Purchase of Apparels and its Impact on Customer Satisfaction (With Reference to Organized Retail Outlets in NCR). i-Manager's Journal on Management, 6(1), 20.

FATIMA, I., WASIM, M., \& REHMAN, S. (2011). DIETARY EXPOSURE TO ESSENTIAL AND TOXIC ELEMENTS FROM FRESH, PASTEURISED AND POWDER MILK SAMPLES FROM PAKISTAN. Nucleus, 48(4), 315-322.

Javaid, S., Gadahi, J., Khaskeli, M., Bhutto, M., Kumbher, S., Panhwar, A., \& others. (2009). Physical and chemical quality of market milk sold at Tandojam, Pakistan. Pakistan Veterinary Journal, 29(1), 27-31.

Jawaid, S., Talpur, F. N., Nizamani, S. M., Memon, N. N., \& Khaskheli, A. A. (2015). Quantification of oxytocin residues in dairy milk from Sindh, Pakistan. International Journal of Food Science I\& Technology, 50(7), 1640-1643.

Khaqan, M., Siddiqui, A., \& Siddiqui, K. (2016). Brand Failure in Pakistan: Content Analytic Findings. Journal of Marketing Management and Consumer Behavior, 1(3).

Pakistan, G. (2010). Economic Survey of Pakistan. Economic Affairs Wing, Finance Ministry, Islamabad.

Shaikh, N., Marri, A., Qureshi, B., Pathan, M., Suthar, V., Qureshi, N. A., . . Kumari, V. (2016). Extent of Formalin and Cane Sugar Adulteration and its Impact on 
Physicochemical Attributes of Milk Sold at Hyderabad and its Outskirts. Int J Sci Res, $5,827-832$.

Solomon, M. R. (2014). Consumer behavior: Buying, having, and being (Vol. 10). Prentice Hall Engelwood Cliffs, NJ. 